\title{
Clara Cell 10-kDa Protein is a Sensitive Biomarker to Identify Th2 Subtype Inflammatory Phenotypes of Asthma
}

\section{Meijia Wang}

Tongji Hospital of Tongji Medical College of Huazhong University of Science and Technology https://orcid.org/0000-0002-3596-1229

\section{Kun Tang}

Tongji Hospital of Tongji Medical College of Huazhong University of Science and Technology

\section{Pengfei Gao}

Department of Respiratory and Critical Care Medcine, the First Affiliated Hospital of Henan Universitily of Science and Technology, Luoyang

\section{Yanjiao Lu}

Department of Respiratory and Critical Care Medicine,National Clinical Research Center of Respiratory Disease,Key Laboratory of Pulmonary Disease of Health Minisity, Tongji Hospital, Tongji Medical College, Huazhong University of Science and Technology

\section{Shanshan Wang}

Tongji Hospital of Tongji Medical College of Huazhong University of Science and Technology Jianping Zhao

Tongji Hospital of Tongji Medical College of Huazhong University of Science and Technology Jungang Xie ( $\nabla$ xiejjgg@hotmail.com )

Tongji Hospital of Tongji Medical College of Huazhong University of Science and Technology https://orcid.org/0000-0001-9037-3027

\section{Research}

Keywords: Asthma, CC10, Th2-high asthma, Th2-low asthma

Posted Date: October 27th, 2020

DOI: https://doi.org/10.21203/rs.3.rs-96170/v1

License: (c) (i) This work is licensed under a Creative Commons Attribution 4.0 International License. Read Full License 


\section{Abstract}

Background: Clara cell 10-kDa protein (CC10) is one of the most abundant proteins in bronchoalveolar lavage fluis and has been described as a biomarker for airway obstructive diseases. CC10 possesses the properties of suppression Th2 cell differentiation and Th2 cytokine production. In this study, we aimed to determine whether $\mathrm{CC} 10$ can be a sensitive biomarker to identify Th2 phenotypes of asthma.

Methods: Adults with asthma $(n=50)$ were categorized as Th2-high asthma or Th2-low asthma according to serum IgE, blood eosinophils and fractional exhaled nitric oxide (FeNO). Patients were classified as Th2-high asthma when two or more biomarkers (high $\operatorname{lgE} \geq 100 \mathrm{IU} / \mathrm{mL}$, high Eos $\geq 300 / \mu \mathrm{L}$, or high FeNO $\geq 30 \mathrm{ppb}$ ) were elevated, and classified as Th2-low asthma when one or no biomarker was elevated. Enzyme-linked immunosorbent assay (ELISA) was used to assess the CC10 and periostin levels in plasma. All participants underwent sputum induction, and different types of inflammatory cells were counted.

Results: The plasma CC10 levels from patients with Th2-low asthma were higher than patients with Th2high asthma $\triangle \mathrm{P}<0.001$. The receiver-operating characteristic (ROC) analysis showed a sensitivity of 0.73 and specificity of 0.74 for plasma CC10 of $19.76 \mathrm{ng} / \mathrm{ml}$ to distinguish asthmatic patents with Th2-high phenotype or Th2-low phenotype. Correlation analysis indicated that the plasma CC10 levels were inversely correlated with plasma periostin, sputum eosinophil and negative logPD20 (pष0.05), however positively correlated with sputum neutrophil percentages and FEV1 \% predictions ( $\mathrm{p} \otimes 0.05)$.

Conclusions: The plasma CC10 was potentially useful in predicting Th2-high and Th2-low phenotypes in patients with asthma. Lower plasma CC10 was associated with enhanced airway hyperresponsiveness, Th2-high inflammation and subsequent airflow limitation.

\section{Introduction}

Bronchial asthma is commonly occurred in population, however the pathophysiological mechanisms and phenotypes are highly diverse. Despite the significant effort that has been directed at defining the various phenotypes of asthma, the biomarkers of these different phenotypes were not clear ${ }^{[1]}$. Phenotype-specific therapies for targeted and personalized approaches according to defined phenotypes had been suggested to improve the disease outcomes in asthmatic patients ${ }^{[2]}$. Therefore, the discovering of accurate biomarkers for different phenotypes of asthma was of critical importance.

Asthma historically was characterized as Th2-mediated inflammation disease, however researches on the pathogenesis of asthma had demonstrated that only a subgroup of asthmatic patients exhibited increased Th2 inflammation in the airway ${ }^{[3]}$. Th2-high asthma demonstrated enhanced bronchial hyperresponsiveness, higher serum IgE, increased blood and airway eosinophilia, and reduced lung function and frequent exacerbations. Patients with Th2-high asthma were sensitive to the treatments of corticosteroid therapy and Th2-biologic agent ${ }^{[3,4]}$. This "Th2 signature" was identified by genome-wide 
transcriptional analysis of bronchial epithelial brushings, in which three genes: periostin, chloride channel accessory 1 (CLCA1) and Serpin $\beta 2$ (SerpinB2), were found specifically induced by interleukin (IL)-4 or IL13 in vitro ${ }^{[5]}$. However, bronchial epithelial brushing from patients with asthma was considered to be an invasive, costly, complex to perform, therefore had not been widely used for clinics and researches ${ }^{[6]}$. Many other noninvasive markers such as serum IgE, blood and sputum eosinophil count, FeNO and serum periostin were stable indicators of the inflammatory states of asthmatics and surrogate biomarkers of Th2-driven asthma ${ }^{[7,8]}$. However, their diagnostic accuracies in detecting Th2-high asthma remains controversial. The predicting results were potentially influenced by factors other than asthma, therefore had not been widely recognized ${ }^{[3]}$. For this reason, it is necessary to explore alternative and accurate biomarkers for distinguishing Th2-high and Th2-low asthma.

Club cell 10-kDa protein (CC10), belongs to the secretoglobin family, is primarily produced by nonciliated club cells in the distal airway and nasal epithelial cells, and can be detected in the circulation ${ }^{[9,10]}$. It was reported that $\mathrm{CC} 10$ can inhibit inflammatory through the suppression of phospholipase A2 activity, downregulation of Th2 cell differentiation, and inhibition of inflammatory cytokine production [11]. Previous studies suggested that adeno-associated virus (AAV)2/9-CC10 vector virus significantly reduced airway hyperresponsiveness, Th2 cytokines and eosinophilia in the lungs of OVA-sensitized mice ${ }^{[12]}$. And serum CC10 levels in asthmatic patients had been shown significantly lower than in control subjects ${ }^{[13]}$. However, whether the expression of CC10 differ in Th2-high asthma versus Th2-low asthma were still unknown. Therefore, in this study, we aimed to examine the ability of serum CC10 to predict asthma inflammatory subtypes.

\section{Materials And Methods}

\section{Subjects}

Fifty asthmatic patients aged 18-65 years were recruited at Tongji Hospital. The diagnosis of asthma was performed based on the Global Initiative for Asthma (GINA) guidelines. All participants were diagnosed with symptomatic asthma and demonstrated symptoms of airways hyperresponsiveness (provacative dose of methacholine causing a 20\% drop in FEV1 $<2.5 \mathrm{mg}, \mathrm{PD} 20 \mathrm{FEV} 1<2.5 \mathrm{mg}$ ) and/or bronchodilator responsiveness (> 12\% improvement in FEV1\% predicted following inhalation of $200 \mu \mathrm{g}$ salbutamol). No participant were current smokers or had a history over 10 pack-years. Participants were excluded when oral corticosteroids were performed or a respiratory tract infection was diagnosed in the previous 4 weeks. Blood and sputum samples were collected from all participates at their visits for this study. Written informed consents were performed for all participates. This study was approved by the ethics committee of Tongji Hospital, Tongji Medical College, Huazhong University of Science and Technology.

\section{Sputum Induction and Analysis}


Sputum induction with hypertonic saline $(4.5 \%)$ was performed as described previously ${ }^{[14]}$. Sputum portions were isolated and dispersed using dithiothreitol. Total inflammatory cell counts and viability tests were performed. Aliquots of sputum samples were prepared by Cytospin and stained with MayGrunwald Giemsa, subsequently, differential cell counts for positive stained cells were performed for every 400 nonsquamous cells. Results for different sputum cell type proportions were displayed as percentage over total nonsquamous cell count.

\section{Enzyme-linked immunosorbent assay (ELISA)}

Plasma CC10 (R\&D Systems, Minneapolis, MN, USA) and periostin (Eton Bioscience, San Diego, CA, USA) were measured with a sandwich ELISA according to the manufacturer's protocols.

\section{Statistical analysis}

All data were displayed as means \pm SD. All statistical analyses were carried out by GraphPad Prism 5 software (GraphPad, San Diego, CA, USA). Unpaired t-tests were performed for normal distributed data, while nonparametric tests were applied for nonnormal distributed data. Correlation analysis were performed by Spearman Rank Order Correlation. Receiver-operating characteristic (ROC) curves were generated for the determination of the cut-off value for the ability of plasma CC10 levels to differentiate between Th2-high and Th2-low phenotype asthma according to curve points closest to $(0,1)$. Sensitivities and specificities were calculated according to the identified optimal cut-points. $P$ value $<0.05$ were considered as statistically significant.

\section{Results}

\section{Subjects characteristics}

Clinical characteristics of all participants were summarized as in Table 1. In this study patients were defined as Th2-high asthma or Th2-low asthma according to the levels of serum IgE, blood eosinophils, and FeNO. Participants were classified as Th2-high asthma as follows elevation in two or more biomarkers: high $\operatorname{lgE} \geq 100 \mathrm{IU} / \mathrm{mL}$, high blood eosinophils $\geq 300 / \mu \mathrm{L}$, high FeNO $\geq 30 \mathrm{ppb}$, and Th2-low asthma as elevation in one or no biomarkers. As the results, no significant difference in demographics, duration of asthma and mean FEV1 at baseline between Th2-high and Th2-low asthma were demonstrated. Meanwhile, significantly higher sputum eosinophil percentages were found in Th2-high asthmatic patients than Th2-low asthmatic patients. However, no significant difference was observed in sputum neutrophil percentages between the two groups. 
Table 1

Patient characteristics

\begin{tabular}{|lll|}
\hline & Th2-high asthma $(\mathbf{n}=\mathbf{2 4})$ & $\begin{array}{l}\text { Th2-low asthma } \\
(\mathbf{n}=\mathbf{2 6})\end{array}$ \\
\hline Age(y) & $39.04 \pm 9.37$ & $44.92 \pm 12.18$ \\
\hline Sex (male/female) & $14 / 10$ & $10 / 16$ \\
\hline Duration of asthma (y) & $6.33 \pm 1.59$ & $5.73 \pm 1.29$ \\
\hline FEV1 (\% predicted) & $80.18 \pm 20.28$ & $85.63 \pm 23.03$ \\
\hline FEV1/FVC (\%) & $64.51 \pm 12.54$ & $67.36 \pm 14.05$ \\
\hline Sputum eutrophil,\% & $47.42 \pm 5.71$ & $57.56 \pm 5.17$ \\
\hline Sputum eosinophil,\% & $24.31 \pm 4.62$ & $9.88 \pm 1.81^{\star \star}$ \\
\hline $\begin{array}{l}\text { Values are presented as mean } \pm \text { SD. FEV1, forced expiratory volume in } 1 \text { sec; FVC, forced vital } \\
\text { capacity; **P }<0.001 \text { compared with Th2-high asthma }\end{array}$ \\
\hline
\end{tabular}

\section{Distinct CC10 expression in Th2-high and Th2-low phenotype asthma}

Plasma CC10 concentrations were measured by ELISA. Plasma CC10 concentrations were higher in Th2low asthmatic patients compared with Th2-high asthmatic patients $(27.07 \pm 2.05 \mathrm{ng} / \mathrm{ml}$ versus $17.87 \pm$ $1.68 \mathrm{ng} / \mathrm{ml}$, respectively, $\mathrm{p}<0.01)$.

\section{ROC curves for the sensitivity and specificity evaluations of plasma CC10 to detect airway Th2 inflammation}

To estimate the diagnostic value of the plasma CC10 for discriminating between Th2-high asthmatic patients and Th2-low asthmatic patients, ROC curves analysis was performed. As shown in the Fig. 4, the area under the curve (AUC) of CC10 was 0.78. When the cutoff for plasma CC10 was selected as $19.76 \mathrm{ng} / \mathrm{ml}$, the sensitivity and specificity for differentiating Th2-high asthmatic patients from asthma patients were $73 \%$ and $74 \%$, respectively.

\section{Signal correlation analyses between plasma $\mathrm{CC} 10$ with plasma periostin and sputum differential inflammatory cell counts in asthmatic patients}

Periostin is a systemic biomarker of airway eosinophilia in asthmatic patients, by showing a significant correlation with sputum eosinophils ${ }^{[15]}$. To investigate the association between plasma CC10 levels and eosinophilic airway inflammation, we analysed the correlation between plasma CC10 levels, plasma periostin and sputum differential inflammatory cell counts in asthma. We found that the plasma CC10 levels were negatively correlated with plasma periostion levels $(r=-0.4008, p=0.0085)$ and sputum eosinophil percentages $(r=-0.3578, p=0.0343)$, and positively correlated with sputum neutrophil 
percentages $(r=0.3136, p=0.0431)$. However, no association between plasma CC10 levels and sputum macrophage percentages was found.

\section{Signal correlation analyses between plasma $\mathrm{CC} 10$ with pulmonary lung function in asthmatic patients}

We further analyzed the association between plasma CC10 levels and pulmonary function and found that plasma CC10 levels were positively correlated with FEV1\% pred $(r=0.343, p=0.02)$, and negatively correlated with negative log PD20 $(r=0.349, p=0.04)$, however not correlated with FVC\% pred or FEV1/FVC ratio in asthmatic patients.

\section{Discussion}

The present study demonstrates that plasma CC10 levels in Th2-high asthma were significantly lower than that in Th2-low asthma. To evaluate the potential diagnostic usage of plasma CC10 for prediction asthma phenotypes, a ROC curve analysis was performed. When the cut off value for plasma CC10 to distinguish asthmatic patients to Th2-high or Th2-low asthma was $19.76 \mathrm{ng} / \mathrm{mL}$, the sensitivity and specificity were 0.73 and 0.74 , respectively. The single analysis revealed that $\mathrm{CC} 10$ was negatively related with airway eosinophilic inflammation and airway hyperresponsiveness, and positively correlated with neutrophilic inflammation and airway obstruction. Collectively, plasma CC10 level was demonstrated as a potential clinical diagnostic biomarker for the distinguish of Th2-high and Th2-low asthma.

The aim of personalized medicine in asthma was that individualized treatment based on noninvasive biomarkers predicted clinical course and therapeutic efficacy ${ }^{[16]}$. It was not a research strategy, but rather an up-to-date clinical practice that clinicians classify patients into more homogeneous groups with similar prognosis and/or treatment needs ${ }^{[17]}$. Although airway sampling from bronchoscopy and induced sputum enabled the direct characterizations of airway inflammation, these modalities were invasive to patients, time consuming, labor intensive, technically variable across facilities and difficult to implement widely in primary care settings. Also, lack of consensus on technical procedures, quality assurance and diagnostic markers in airway cytology limited the use of such technique ${ }^{[8]}$. Thus, it was potentially beneficial to develop accessible methods for the assessments of airway inflammation.

CC10 has been used as a potential surrogate biomarker due to the reasons such as accessible to assess, reproducible, unaffected by steroids and associated with disease pathophysiology ${ }^{[18]}$. Studies demonstrated that the concentration of $\mathrm{CC} 10$ in circulation was a sensitive biomarker of epithelium damage ${ }^{[10]}$, while decreased CC10 had been consistently observed in chronic airway diseases such as chronic obstructive pulmonary disease (COPD) and asthma ${ }^{[19,20]}$. In this study, we demonstrated that plasma CC10 was significantly decreased in Th2-high asthma. Also, single analysis revealed that plasma CC10 was negatively correlated with sputum eosinophil and negatively with sputum neutrophils, supporting our findings that the level of CC10 is decreased in eosinophil-dominated inflammations (Th2high asthma) and increased in neutrophil-associated inflammations (Th2-low asthma). Previous studies suggested that CC10 inhibited Th2 cell differentiation, Th2 cytokine generation and pulmonary 
eosinophilia ${ }^{[21,22]}$. Thus, eosinophilia in patients with Th2-high asthma was ascribed to deficits of circulating $\mathrm{CC} 10$. Alternatively, the plasma $\mathrm{CC} 10$ levels was negatively correlated with serum periostin, which was considered to be a sensitive biomarker to reflect airway eosinophilia among several biomarkers, including blood eosinophils and exhaled nitric oxide ${ }^{[23]}$. Taken together, a negative correlation was found between airway eosinophilic inflammation and plasma CC10 levels, providing evidence that $\mathrm{CC} 10$ deficits was a reflection of Th2-driven inflammation in the airway. Other studies found that CC10 expression in lung tissue was regulated by inflammatory cytokines. IL-4 and IL-13 inhibited CC10 production ${ }^{[24]}$, whereas interferon (INF) $-\mathrm{y}$ and IL-10 could promote $\mathrm{CC} 10$ production ${ }^{[25}$, 26]. The counter effect of Th1 and Th2 cytokines on CC10 production may ensure the stability of discrepant expression in different asthma phenotypes. Thus, the plasma CC10 is an important index for the classification of inflammation in asthmatic patients.

In addition to airway inflammation, plasma CC10 levels might be a surrogate predictor of airway obstruction and bronchial hyperresponsiveness. Previous study demonstrated that serum CC10 levels were positively correlated with lung function in patients with asthma and COPD ${ }^{[27,28]}$. In our study, we observed that decreased plasma CC10 levels were associated with airflow limitation and damaged lung functions among asthmatic patients. Concurrently, we found a negatively correlation between plasma CC10 levels and bronchial hyperresponsiveness in asthmatic patients, which was in line with a recently report showing that low serum CC16 enhanced airway hyperresponsiveness to methacholine challenge in adults ${ }^{[29]}$. This scenario demonstrated that CC10 alleviated airway obstruction and hyperresponsiveness as a result of inhibition of Th- 2 inflammation in asthma.

Several clinical studies demonstrated that low circulating CC10 levels were a risk factor for accelerated lung function decline, and associated with the progressions of COPD ${ }^{[30,31]}$. However, it was still unclear that if the levels of circulation CC10 was correlated with the progression of asthma. Also, the recombinant CC10 protein was verified to be valuable in the treatments of COPD mice through the inhibition of the pro-inflammatory factor productions ${ }^{[32]}$. Meanwhile, no study was performed to evaluated whether recombinant CC10 was valuable in the treatment of asthma patients, especially in Th2-high asthma. Therefore, further studies were necessary for the investigation of their efficacy in monitoring disease progressions and treatments in asthma.

\section{Conclusion}

In summary, plasma CC10 levels differed significantly between Th2-high asthma and Th2-low asthma. In addition, low CC10 levels were potentially used as biomarkers for Th2-high inflammation, subsequent airflow limitation and airway hyperresponsiveness enhancement in asthmatic patients.

\section{Abbreviations}


CC10: Clara cell 10-kDa protein; FeNO: fractional exhaled nitric oxide; ELISA: enzyme-linked immunosorbent assay; ROC: receiver-operating characteristic; CLCA1: chloride channel accessory 1 ; SerpinB2: Serpin 32 ; AAV 2/9: adeno-associated virus 2/9; GINA: Global Initiative for Asthma guidelines; FEV1: forced expiratory volume in one second; PD20: provacative dose of methacholine causing a $20 \%$ drop in FEV1; SD: standard deviation $\triangle A U C$ : area under the curve; FVC: forced vital capacity; COPD: chronic obstructive pulmonary disease

\section{Declarations}

\section{Ethics approval and consent to participate}

The ethics committee of Tongji Hospital, Tongji Medical College, Huazhong University of Science and Technology approved this study. All procedures performed in the study involving human participants were in accordance with the ethical standards of the institutional research committee

\section{Consent for publication}

Not applicable

\section{Availability of data and materials}

Not applicable.

\section{Competing interests}

The authors declare that they have no competing interests.

\section{Funding}

This study was supported by the National Natural Science Foundation of China (No. 81973986, 81570033), the National key basic research and development program (973 Program, No. 20I5CB553403), and the National Key R\&D Program of China (2016YFC1304500, 2018YFC1311900).

\section{Author contributions}

WM recruited patients, collected, analyzed, and interpreted the data, and wrote the draft. TK, GP, LY, WC recruited patients, collected data. ZJ and XJ conceived and designed the study, recruited patients, and provided overall supervision and critically revised the manuscript. All authors read and approved the final manuscript.

\section{Acknowledgments}

We thank the patients who volunteered for the study; Wang Ni, Shixin Chen and Kun Zhang for spirometry measurement. 


\section{References}

1. Wenzel SE. Asthma phenotypes: the evolution from clinical to molecular approaches. NAT MED. 2012;18ه716-25.

2. Chung KF. Asthma phenotyping: a necessity for improved therapeutic precision and new targeted therapies. J INTERN MED. 2016;279ه192-204.

3. Coverstone AM, Seibold MA, Peters MC. Diagnosis and Management of T2-High Asthma. J Allergy Clin Immunol Pract. 2020;8®442-50.

4. Woodruff PG, Modrek B, Choy DF, Jia G, Abbas AR, Ellwanger A, Koth LL, Arron JR, Fahy JV. T-helper type 2-driven inflammation defines major subphenotypes of asthma. Am J Respir Crit Care Med. 2009;180囚388-95.

5. Woodruff PG, Boushey HA, Dolganov GM, Barker CS, Yang YH, Donnelly S, Ellwanger A, Sidhu SS, Dao-Pick TP, Pantoja C, Erle DJ, Yamamoto KR, Fahy JV. Genome-wide profiling identifies epithelial cell genes associated with asthma and with treatment response to corticosteroids. Proc Natl Acad Sci U S A. 2007;104ه15858-63.

6. Fatemi F, Sadroddiny E, Gheibi A, Mohammadi FT, Kardar GA. Biomolecular markers in assessment and treatment of asthma. RESPIROLOGY. 2014;198514-23.

7. Busse WW, Holgate ST, Wenzel SW, Klekotka P, Chon Y, Feng J, Ingenito EP, Nirula A. Biomarker Profiles in Asthma With High vs Low Airway Reversibility and Poor Disease Control. CHEST. 2015;148囚1489-96.

8. Pavord ID, Afzalnia S, Menzies-Gow A, Heaney LG. The current and future role of biomarkers in type 2 cytokine-mediated asthma management. CLIN EXP ALLERGY. 2017;47ه148-60.

9. Liu Z, Lu X, Zhang XH, Bochner BS, Long XB, Zhang F, Wang H, Cui YH. Clara cell 10-kDa protein expression in chronic rhinosinusitis and its cytokine-driven regulation in sinonasal mucosa. ALLERGY. 2009;64『149-57.

10. Broeckaert F, Bernard A. Clara cell secretory protein (CC16): characteristics and perspectives as lung peripheral biomarker. CLIN EXP ALLERGY. 2000;30ه469-75.

11. Tokita E, Tanabe T, Asano K, Suzaki H, Rubin BK. Club cell 10-kDa protein attenuates airway mucus hypersecretion and inflammation. EUR RESPIR J. 2014;44ه1002-10.

12. Wu CJ, Chen LC, Huang WC, Chuang CL, Kuo ML. Alleviation of lung inflammatory responses by adeno-associated virus 2/9 vector carrying CC10 in OVA-sensitized mice. HUM GENE THER. 2013;24】 48-57.

13. Shijubo N, Itoh Y, Yamaguchi T, Sugaya F, Hirasawa M, Yamada T, Kawai T, Abe S. Serum levels of Clara cell 10-kDa protein are decreased in patients with asthma. LUNG. 1999;177ه45-52.

14. Simpson JL, Scott R, Boyle MJ, Gibson PG. Inflammatory subtypes in asthma: assessment and identification using induced sputum. RESPIROLOGY. 2006;11ه54-61.

15. Jia G, Erickson RW, Choy DF, Mosesova S, Wu LC, Solberg OD, Shikotra A, Carter R, Audusseau S, Hamid Q, Bradding P, Fahy JV, Woodruff PG, Harris JM, Arron JR. Periostin is a systemic biomarker of 
eosinophilic airway inflammation in asthmatic patients. J Allergy Clin Immunol. 2012;130ه647-54.

16. Thomson NC. Novel approaches to the management of noneosinophilic asthma. THER ADV RESPIR DIS. 2016;10ه211-34.

17. Agusti A, Anto JM, Auffray C, Barbe F, Barreiro E, Dorca J, Escarrabill J, Faner R, Furlong LI, GarciaAymerich J, Gea J, Lindmark B, Monso E, Plaza V, Puhan MA, Roca J, Ruiz-Manzano J, SampietroColom L, Sanz F, Serrano L, Sharpe J, Sibila O, Silverman EK, Sterk PJ, Sznajder JI. Personalized respiratory medicine: exploring the horizon, addressing the issues. Summary of a BRN-AJRCCM workshop held in Barcelona on June 12, 2014. Am J Respir Crit Care Med. 2015;191『391-401.

18. Bommart S, Marin G, Molinari N, Knabe L, Petit A, Chanez P, Gamez AS, Devautour C, Vachier I, Bourdin A. Club cell secretory protein serum concentration is a surrogate marker of small-airway involvement in asthmatic patients. J Allergy Clin Immunol. 2017;140®581-4.

19. Guerra S, Vasquez MM, Spangenberg A, Halonen M, Martin RJ. Club cell secretory protein in serum and bronchoalveolar lavage of patients with asthma. J Allergy Clin Immunol. 2016;138\932-4.

20. Laucho-Contreras ME, Polverino F, Gupta K, Taylor KL, Kelly E, Pinto-Plata V, Divo M, Ashfaq N, Petersen H, Stripp B, Pilon AL, Tesfaigzi Y, Celli BR, Owen CA. Protective role for club cell secretory protein-16 (CC16) in the development of COPD. EUR RESPIR J. 2015;45ه1544-56.

21. Johansson S, Wennergren G, Aberg N, Rudin A. Clara cell 16-kd protein downregulates $T(H) 2$ differentiation of human naive neonatal T cells. J Allergy Clin Immunol. 2007;120®308-14.

22. Hung $\mathrm{CH}$, Chen LC, Zhang Z, Chowdhury B, Lee WL, Plunkett B, Chen CH, Myers AC, Huang SK. Regulation of TH2 responses by the pulmonary Clara cell secretory 10-kd protein. J Allergy Clin Immunol. 2004;114『664-70.

23. Nair $P$, Kraft M. Serum periostin as a marker of $T(H)$ 2-dependent eosinophilic airway inflammation. $J$ Allergy Clin Immunol. 2012;130ه655-6.

24. Zhu L, An L, Ran D, Lizarraga R, Bondy C, Zhou X, Harper RW, Liao SY, Chen Y. The Club Cell Marker SCGB1A1 Downstream of FOXA2 is Reduced in Asthma. Am J Respir Cell Mol Biol. 2019;60®695704.

25. Srisodsai A, Kurotani R, Chiba Y, Sheikh F, Young HA, Donnelly RP, Kimura S. Interleukin-10 induces uteroglobin-related protein (UGRP) 1 gene expression in lung epithelial cells through homeodomain transcription factor T/EBP/NKX2.1. J BIOL CHEM. 2004;279ه54358-68.

26. Ramsay PL, Luo Z, Magdaleno SM, Whitbourne SK, Cao X, Park MS, Welty SE, Yu-Lee LY, DeMayo FJ. Transcriptional regulation of CCSP by interferon-gamma in vitro and in vivo. Am J Physiol Lung Cell Mol Physiol. 2003;284囚L108-18.

27. Rava M, Tares L, Lavi I, Barreiro E, Zock JP, Ferrer A, Muniozguren N, Nadif R, Cazzoletti L, Kauffmann F, Anto JM, Guerra S. Serum levels of Clara cell secretory protein, asthma, and lung function in the adult general population. J Allergy Clin Immunol. 2013;132ð230-2.

28. Vestbo J, Edwards LD, Scanlon PD, Yates JC, Agusti A, Bakke P, Calverley PM, Celli B, Coxson HO, Crim C, Lomas DA, MacNee W, Miller BE, Silverman EK, Tal-Singer R, Wouters E, Rennard SI. Changes in forced expiratory volume in 1 second over time in COPD. N Engl J Med. 2011;365ه1184-92. 
29. Zhai J, Insel M, Addison KJ, Stern DA, Pederson W, Dy A, Rojas-Quintero J, Owen CA, Sherrill DL, Morgan W, Wright AL, Halonen M, Martinez FD, Kraft M, Guerra S, Ledford JG. Club Cell Secretory Protein Deficiency Leads to Altered Lung Function. Am J Respir Crit Care Med. 2019;199ه302-12.

30. Guerra S, Halonen M, Vasquez MM, Spangenberg A, Stern DA, Morgan WJ, Wright AL, Lavi I, Tares L, Carsin AE, Dobano C, Barreiro E, Zock JP, Martinez-Moratalla J, Urrutia I, Sunyer J, Keidel D, Imboden M, Probst-Hensch N, Hallberg J, Melen E, Wickman M, Bousquet J, Belgrave DC, Simpson A, Custovic A, Anto JM, Martinez FD. Relation between circulating CC16 concentrations, lung function, and development of chronic obstructive pulmonary disease across the lifespan: a prospective study. Lancet Respir Med. 2015;3凶613-20.

31. Park HY, Churg A, Wright JL, Li Y, Tam S, Man SF, Tashkin D, Wise RA, Connett JE, Sin DD. Club cell protein 16 and disease progression in chronic obstructive pulmonary disease. Am J Respir Crit Care Med. 2013;188ه1413-9.

32. Pang M, Liu HY, Li T, Wang D, Hu XY, Zhang XR, Yu BF, Guo R, Wang HL. Recombinant club cell protein 16 (CC16) ameliorates cigarette smokeinduced lung inflammation in a murine disease model of COPD. MOL MED REP. 2018;18囚2198-206.

\section{Figures}




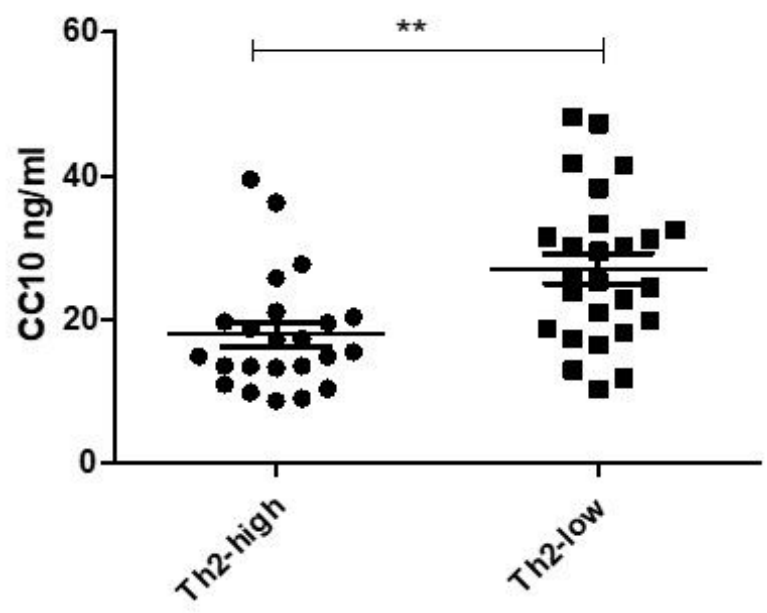

Fig.1

Figure 1

Comparison of plasma CC10 in Th2-high asthma and Th2-low asthma. Data were expressed as means \pm SD. ${ }^{* *} \mathrm{p}<0.01$. 


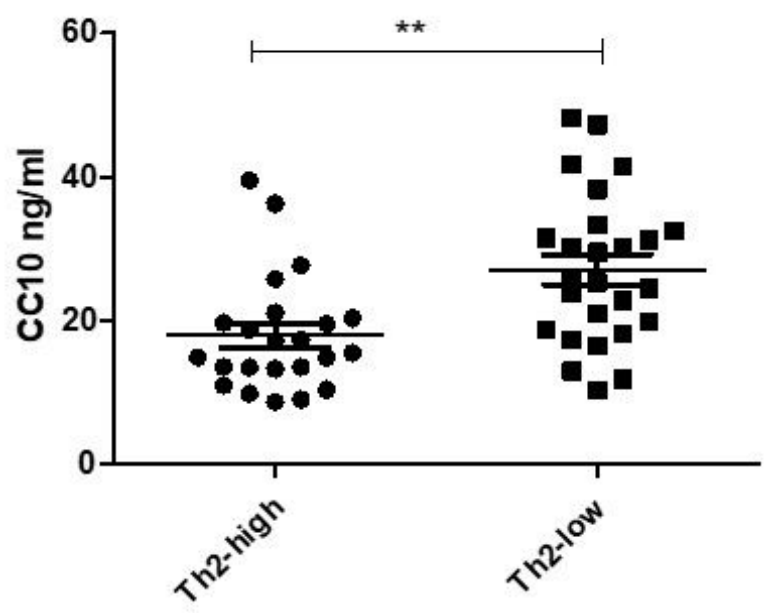

Fig.1

Figure 1

Comparison of plasma CC10 in Th2-high asthma and Th2-low asthma. Data were expressed as means \pm SD. ${ }^{* *} \mathrm{p}<0.01$. 


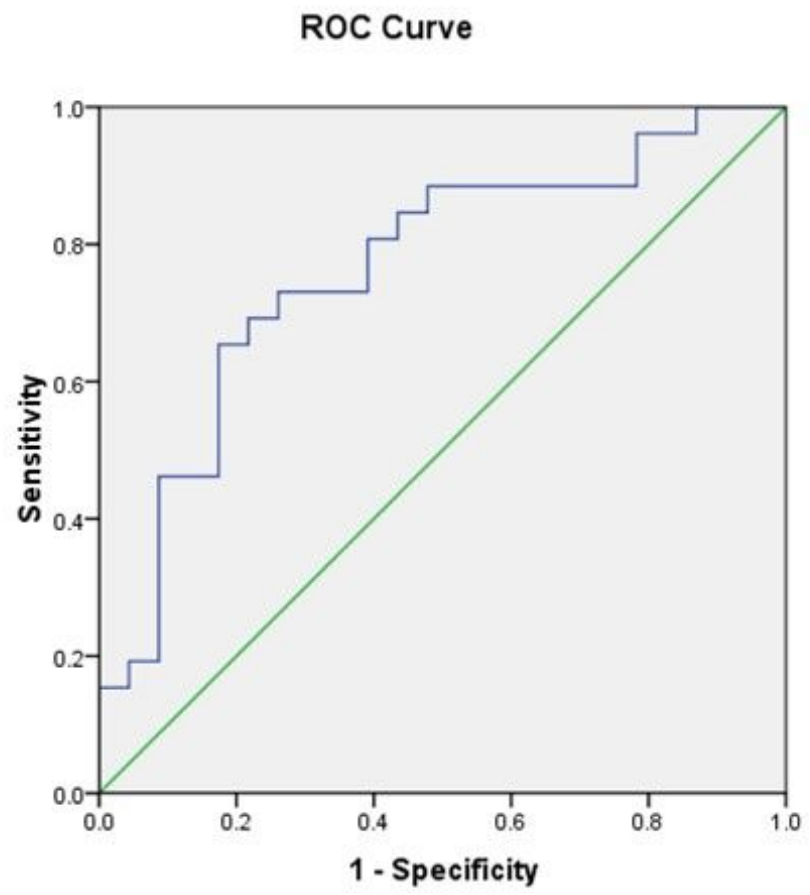

Fig.2

Figure 2

Receiver operating characteristics (ROC) curves of plasma CC10 to assess its potential usage in differentiating Th2-low asthma and Th2-high asthma. The cutoff value on the ROC curves closest to (0, 1) was $19.76 \mathrm{ng} / \mathrm{ml}$. 


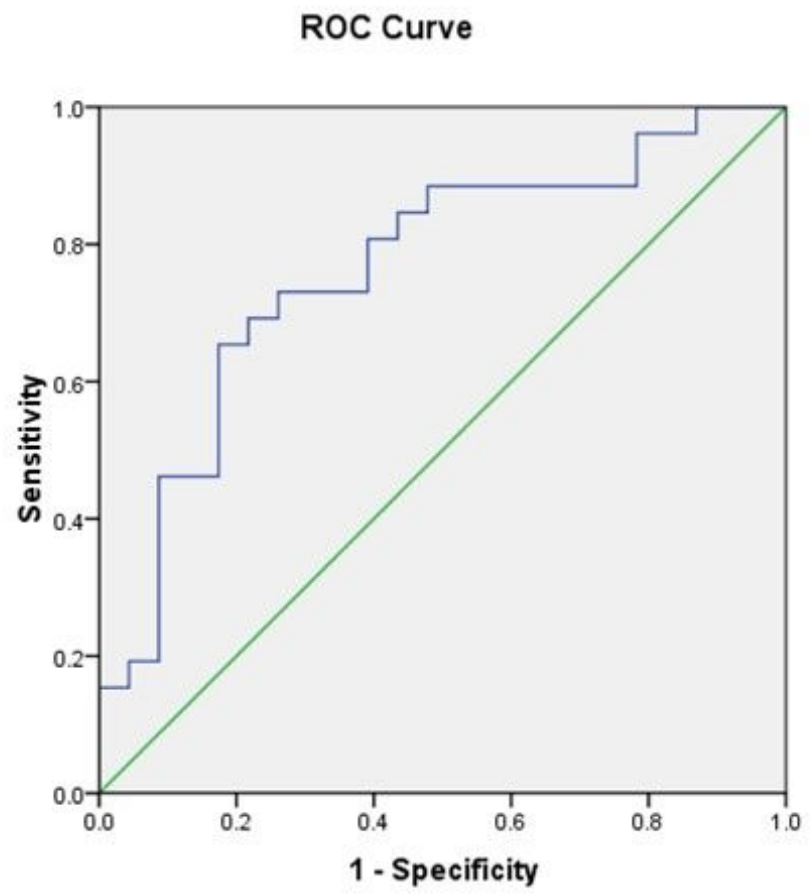

Fig.2

Figure 2

Receiver operating characteristics (ROC) curves of plasma CC10 to assess its potential usage in differentiating Th2-low asthma and Th2-high asthma. The cutoff value on the ROC curves closest to (0, 1) was $19.76 \mathrm{ng} / \mathrm{ml}$. 
A

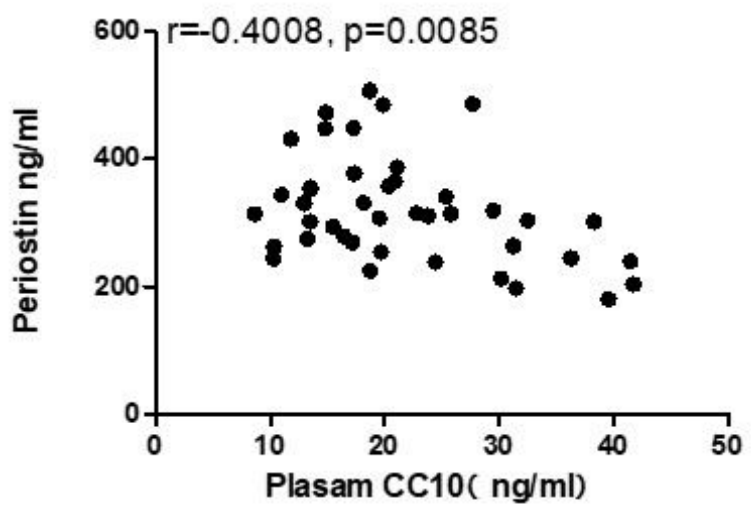

C

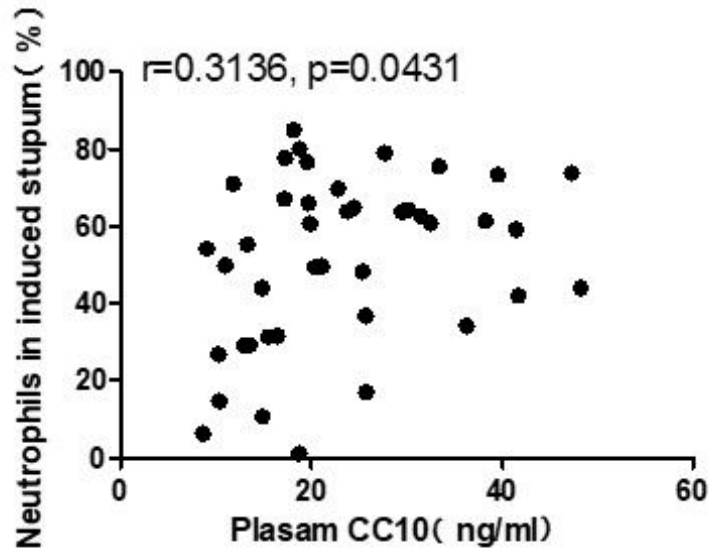

Fig.3
B

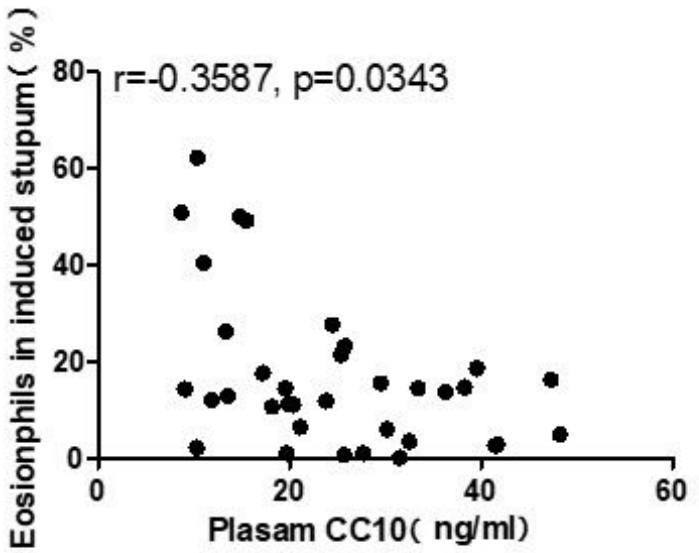

D $。$

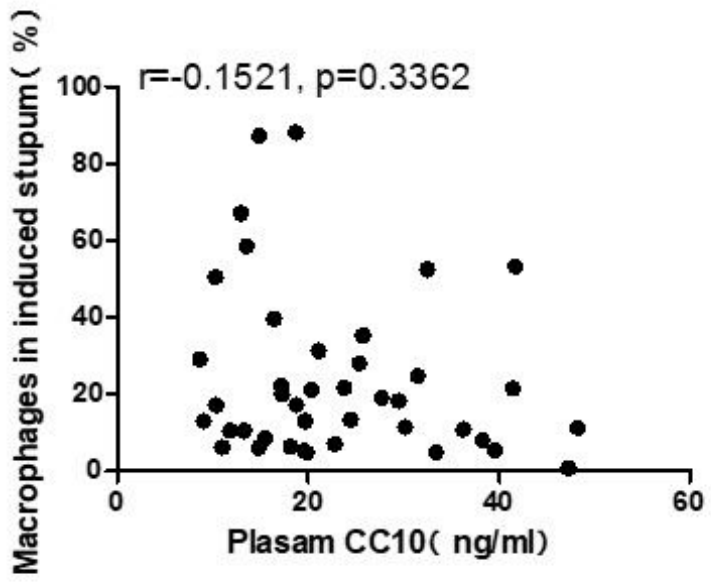

Figure 3

Single correlations between plasma CC10 with plasma periostin and sputum cell differentiations in asthmatic patients. (a) Correlation between plasma CC10 and plasma periostin. (b) Correlation between plasma $\mathrm{CC} 10$ and sputum eosinophils ratio (c) Correlation between plasma CC10 and sputum neutrophils ratio. (d) Correlation between plasma $\mathrm{CC} 10$ and sputum macrophages ratio. 
A

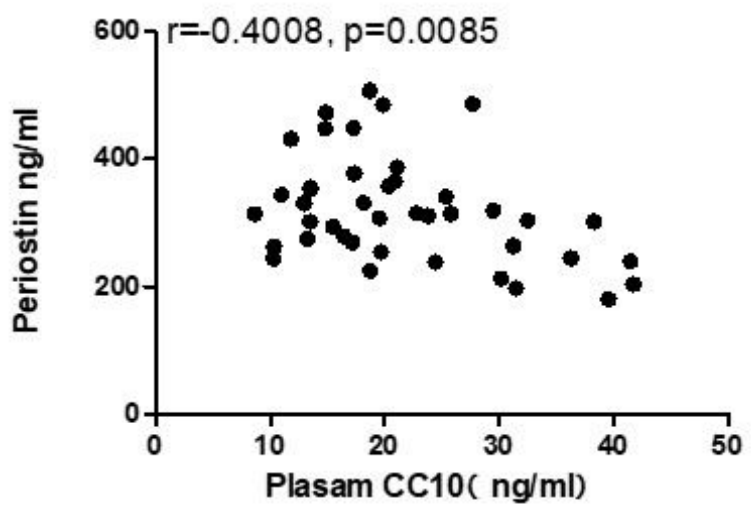

C

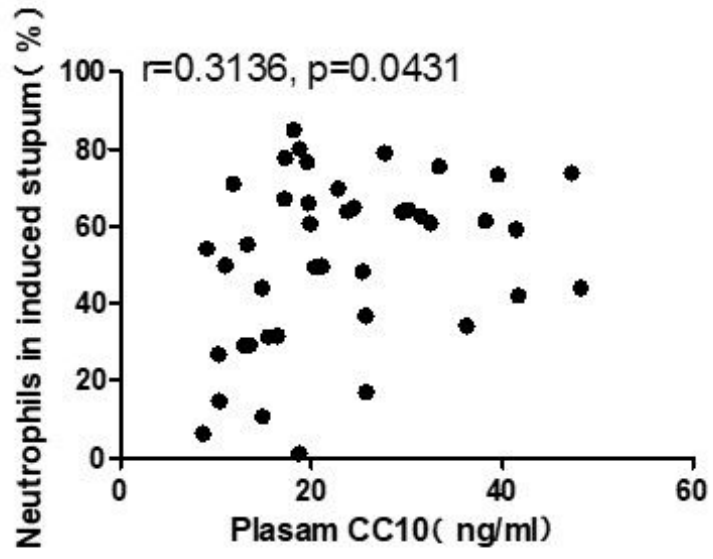

Fig.3

\section{Figure 3}

Single correlations between plasma CC10 with plasma periostin and sputum cell differentiations in asthmatic patients. (a) Correlation between plasma CC10 and plasma periostin. (b) Correlation between plasma CC10 and sputum eosinophils ratio (c) Correlation between plasma CC10 and sputum neutrophils ratio. (d) Correlation between plasma $\mathrm{CC} 10$ and sputum macrophages ratio. 

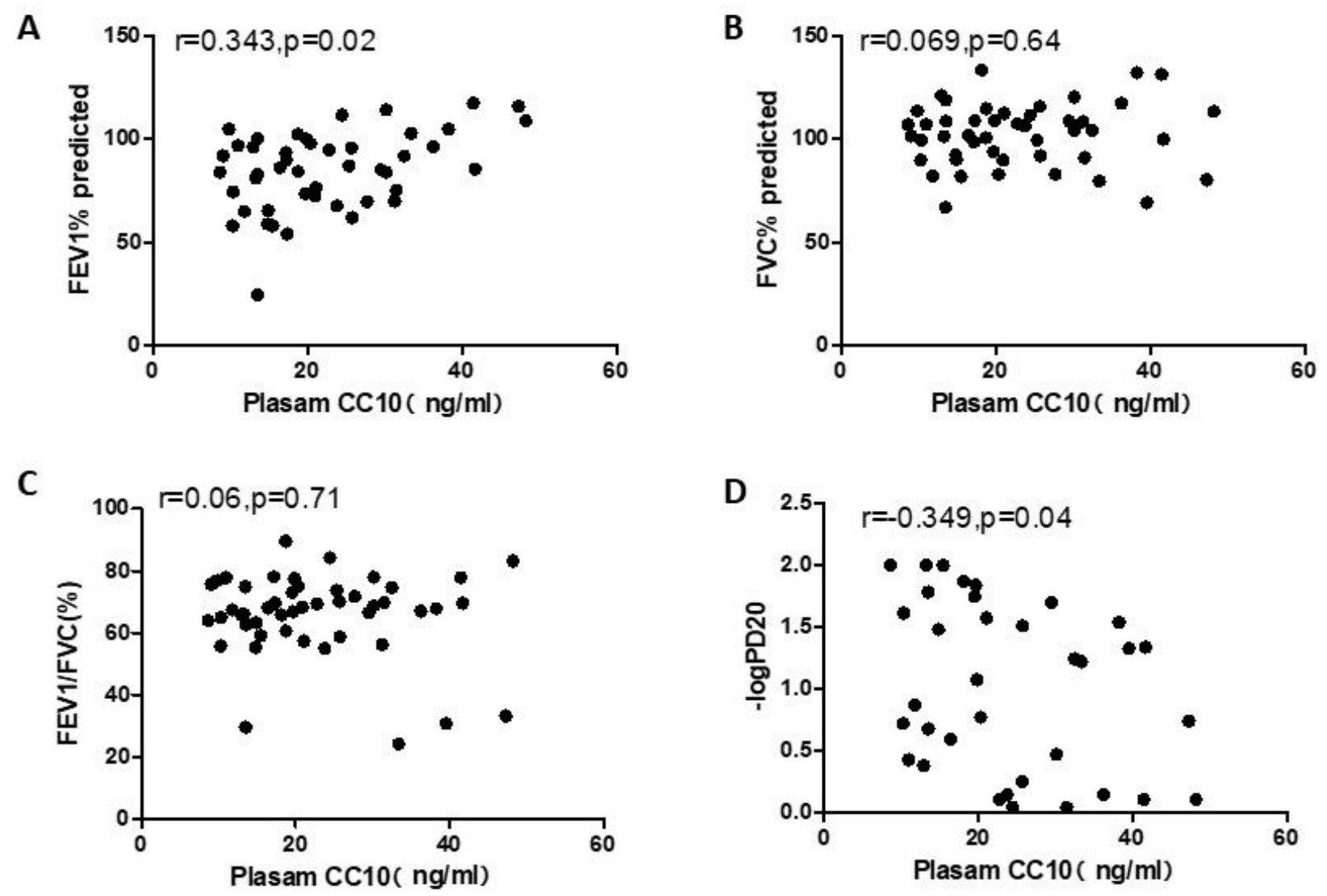

Fig.4

Figure 4

Single correlations between plasma CC10 and respiratory functions in asthmatic patients. (a) Correlation between plasma CC10 and forced volume in one second (FEV1.0), \%pred. (b) Correlation between plasma CC10 and FVC, \%pred. (c) Correlation between plasma CC10 and FEV1/FVC. (d) Correlation between plasma CC10 and negative log PD20. 

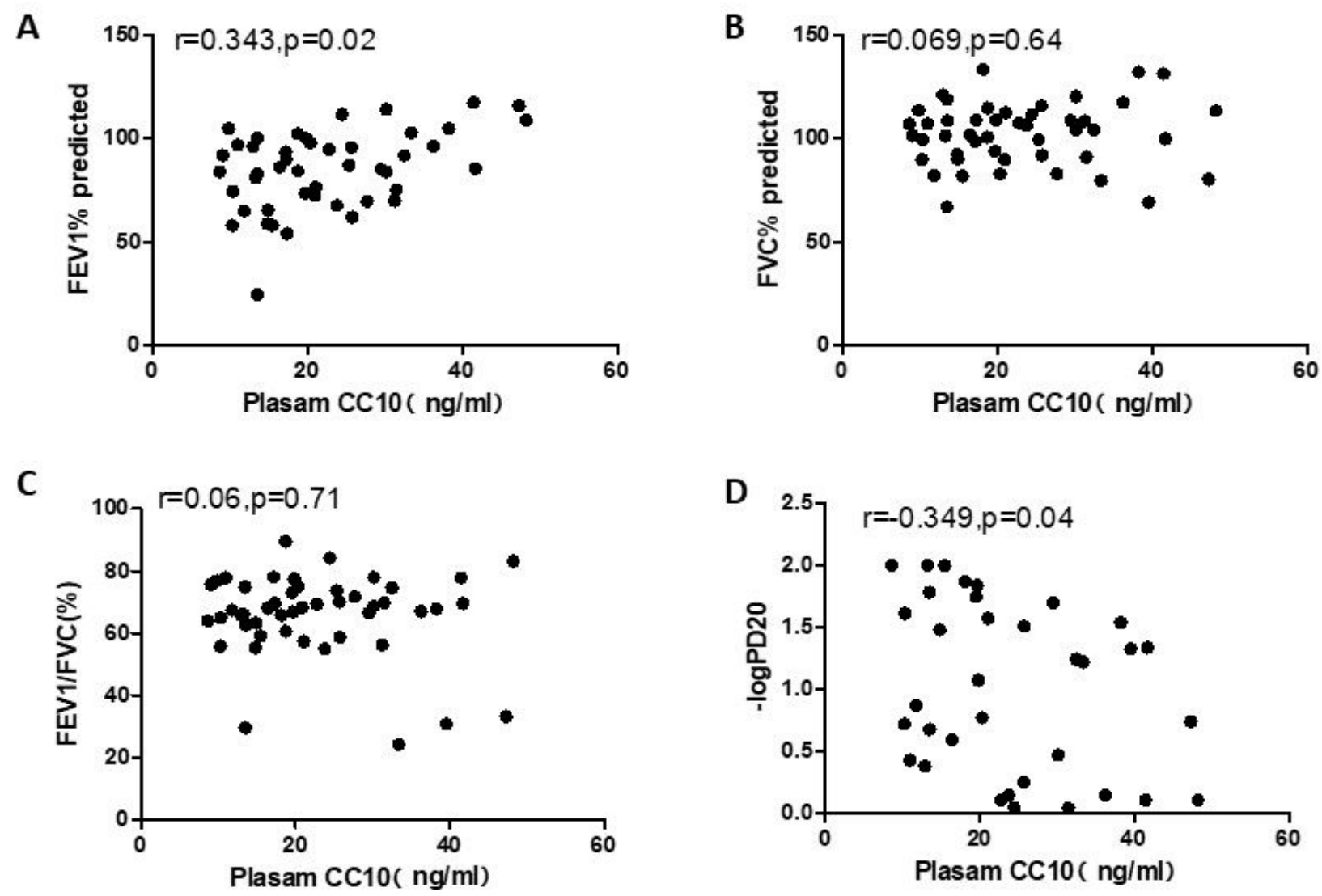

Fig.4

Figure 4

Single correlations between plasma CC10 and respiratory functions in asthmatic patients. (a) Correlation between plasma CC10 and forced volume in one second (FEV1.0), \%pred. (b) Correlation between plasma CC10 and FVC, \%pred. (c) Correlation between plasma CC10 and FEV1/FVC. (d) Correlation between plasma CC10 and negative log PD20. 